\title{
Capability of Iterative Learning Control and Influence of the Material Properties on the Improvement of the Geometrical Accuracy in Incremental Sheet Forming process
}

\author{
A. Fiorentino ${ }^{a^{*}}$, G.C. Feriti ${ }^{\text {a }}$, E. Ceretti ${ }^{a}$, C. Giardini ${ }^{\text {b }}$, \\ ${ }^{a}$ University of Brescia, Dept. of Mechanical and Industrial Engineering, Italy \\ ${ }^{\mathrm{b}}$ University of Bergamo, Dept. of Engineering, Italy \\ Corresponding Author: \\ Antonio Fiorentino \\ Via Branze 38, 25123 Brescia (Italy) \\ antonio.fiorentino@unibs.it \\ (+39) 030.3715582
}

\begin{abstract}
Incremental Sheet Forming (ISF) is a flexible technology that allows the deformation of blank sheets without the need of complex and high cost tools or equipments. One of the main lacks of ISF is the geometrical accuracy which is not comparable with the one achieved by using traditional sheet stamping processes. There are several approaches proposed to enhance this aspect and among them the Authors have developed a method based on an Iterative Learning Control (ILC). ILC consists of a cyclic and progressive error compensation method that improves the quality of the manufactured parts. ILC has been proved to be capable for optimising the production of parts with tight tolerances when dealing with ductile materials (aluminium and steel alloys) and small deformations. In this paper, the method was tested to investigate its capability in a virtual environment. The suggested compensations were checked with Finite Element Method (FEM) so to reduce the number of parts to be manufactured saving time and costs. Moreover, the algorithm was tested considering both a difficult to form material (titanium alloy) and high deformation conditions. The results demonstrated how the precision of ISF processes depends on the blank material properties. Moreover, the capabilities of ILC are shown and discussed.
\end{abstract}

Keywords: Incremental sheet forming, titanium, part precision, material properties, iterative learning control.

\section{Introduction}

Incremental Sheet Forming (ISF) is a forming technique which is almost 50 years old [1] but its requirements in terms of part optimization and control systems delayed its development and application of decades [2]. Nowadays, ISF is an assessed production technology that uses standard Computer Numerical Control (CNC) machines or robots [3] to move a hemispherical head punch in order to deform a blank sheet and to reproduce the part geometry [4]. ISF represents an alternative to traditional sheet forming process thanks to its high flexibility, low cost for small batch productions [5-7] and low energy consumption [8]. Moreover, the process increases the material formability in terms of wall angle [9] and Forming Limit Curve (FLC) [5,10]. Processing time can be reduced using high speed for the punch movement but this may reduce the material formability. Therefore, a trade-off between processing time (and cost) and part feasibility, has to be identified [11]. ISF can be applied for both metal and polymer sheets forming [12]. In particular, the friction between punch and sheet can modify the polymer formability due to the local heating that softens the material [13].

Beside this, the main drawback of ISF is the dimensional accuracy of the formed parts [14] that is in the range of few millimeters $[5,15]$. The main causes are related with phenomena like springback, 
stretching and bending of the sheet [5,16] (Fig. 1), local plasticization [17], bulging [5,18] or low machine stiffness [19].

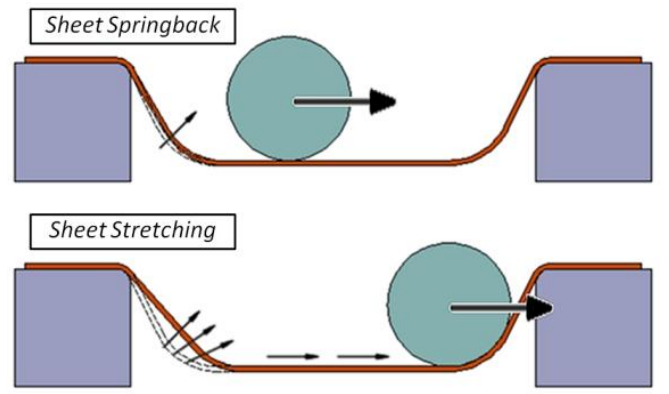

Fig. 1 Springback and stretching action in dieless ISF.

Different strategies have been developed during the years to improve the precision of the process as the use of a counter die, the blank heating or the adoption of off-line and on-line multipass corrections. In fact, it has been demonstrated that the use of a counter die enhances the accuracy of the part thanks to a stiffer clamping system [15]. On the other hand, this represents a reduction of the process flexibility, an increasing of the manufacturing costs and, in case of low cost dies made of polymer or wood, the elasticity of the material significantly influences the accuracy of the produced part [20]. Temperature increases ductility of the material so enhancing the process precision [21,22]. Local heating of $\mathrm{Al}$ sheets was obtained in reference [23] by a $\mathrm{Nd}$ :YAG laser source coupled with a six-axis robot to form conical part. The result was a reduction of the geometrical error to $1.5 \mathrm{~mm}$. In reference [24], tool rotation and surface texturing were proposed for locally heating the blank. Cold forming strategies, as multipass [25], use multiple forming stages to enhance the part accuracy [26,27] and to form $90^{\circ}$ wall angles [28] and more complex features [29]. In reference [30], an iterative correction of the tool-path is performed off-line by using B-spline and morphing techniques. The on-line compensation method in reference [31] was developed using an approach based on the impulse response of the process and on the optimal control theory.

Other authors developed solutions based on Finite Element Method (FEM) to enhance the process precision. In particular, in reference [19], multi-body-system simulations were used to study and to compensate the robot deflections. Moreover, FEM can be used in the process designing phase in order to preliminarily estimate and compensate the geometrical error and, consequently, to produce the corrected parts as reported in reference [32].

The present research focuses on an approach based on the direct modification of the ComputerAided Design (CAD) geometry of the part for improving the geometrical accuracy of the ISF process. The method is based on an Iterative Learning Control (ILC) that allows a cyclic and progressive compensation of the geometrical error of the part until the desired precision is reached. In particular, at each cycle the part is manufactured, the geometrical error is measured and used to modify the part geometry and the tool path. Within this method, it is possible to achieve tight tolerances $( \pm 0.5 \mathrm{~mm})$ when dealing with ductile materials (aluminium and steel alloys) [33-35] and small deformations [34,35].

This paper investigates new capabilities of developed ILC that have not been considered in previous works. In particular, it focuses on the possibility to apply the ILC to Finite Element Method (FEM) simulations so to carry out the ILC cycles in a virtual environment so reducing the amount of parts to be manufactured in the experimental testing phase. The ILC has already been tested in a previous research on asymmetrical parts only in the cases of low deformations (i.e. low step depth $\Delta \mathrm{z}$ of the punch path) and on easy to form materials (Al 1050A and DC04) [33,35]. For these reasons, the present research focuses on more severe testing conditions in terms of material formability and higher deformation step $\Delta z$. In particular, tests were run adopting a higher step depth and extending the set of materials to the hard to cold-form Ti CP Gr2 alloy. Results highlighted the capability of 
the ILC method and how the blank material properties influence the accuracy of the FEM model, of the geometrical precision achievable with this method and of the ISF process in general.

\section{ILC method description}

The method consists of an iterative procedure where the part is incrementally formed, measured and the geometrical error is calculated on the whole part by comparing its geometry with the target one. Once the error is known, the part geometry is corrected according to the error so obtaining a new geometry to be manufactured. The procedure keeps cycling until a convergence criterion is satisfied. The criterion is selected on the base of the specific process or part needs and, in this research, it corresponds to a stable error scattering within a variation of $\pm 5 \%$ (i.e. further iterations do not lead to significant improvements of the part accuracy).

This type of approach is called Iterative Learning Control [36] of a system and consists of the iterative modification of the input so to minimize the output error. Moreover, it does not require an a priori knowledge and, therefore, it is very versatile and can be applied to keep under control all cyclic processes.

Fig. 2 reports the scheme of an ILC procedure at the $k$-th cycle where the system receives the input $u_{k}(t)$ and returns the output $y_{k}(t)$. The error for the $k$-th cycle $e_{k}(t)$ is the difference between $y_{k}(t)$ and the desired output $y_{d}(t)$ as reported in (1). Moreover, the variable $t$ belongs to the domain of the system.

$$
e_{k}(t)=y_{k}(t)-y_{d}(t)
$$

The input of the next cycle $u_{k+1}(t)$ is estimated as a function of the previous input $u_{k}(t)$ and the subsequent error $e_{k}(t)$ as reported in (2):

$$
u_{k+1}(t)=f\left(u_{k}(t), e_{k}(t)\right)
$$

The iteration continues until the norm of the error $\left\|e_{k}(t)\right\|$ reaches its minimum. Therefore, being $u^{*}(t)$ the input minimizing $\left\|e_{k}(t)\right\|$, the ILC converges when (3) is respected.

$$
\lim _{k \rightarrow \infty} u_{k}(t)=u^{*}(t)
$$

In the application of the ILC method to the ISF process, the domain of the system is the set of points that belongs to the part surface $S(t \in S)$, the input $u_{k}(t)$ is the CAD geometry of the part to form, the output $y_{k}(t)$ is the actual part geometry that is obtained, the desired output $y_{d}(t)$ is the target geometry and the error $e_{k}(t)$ is the geometrical error map of the actual part. In particular, $e_{k}(t)$ is estimated according to (1) after aligning $y_{k}(t)$ and $y_{d}(t)$ geometries. They are aligned by minimizing the global error instead of using a single and predefined coordinate system. In this way, the comparison is performed under the functional point of view and in accordance with the "Profile of a surface" tolerance $\square$ [37] instead of a mere comparison of coordinates. Finally, the toolpath $t p_{k}(t)$ used in the ISF process is calculated from $u_{k}(t)$ and the process parameters set $v(t)$ which does not change during the iterations.

The CAD geometry $u_{k+1}(t)$ used for the next iteration is defined on the base of its value $u_{k}(t)$ and the error $e_{k}(t)$ at the present step (at the first step $y_{0}(t)=y_{d}(t)$ ). In particular, $u_{k+1}(t)$ is calculated according to equation (2) using the linear combination described in (4) where $T_{u}(z)$ and $T_{e}(z)$ are variable linear weights (i.e. in general they could depend on the position, error value, ...) respectively for $u_{k}(t)$ and $e_{k}(t)$.

$$
u_{k+1}(t)=T_{u}(z) \cdot u_{k}(t)-T_{e}(z) \cdot e_{k}(t)
$$

The correction weights have to be set to guarantee the convergence of the algorithm and, according to previous works reported in references [33-35,38], suitable values of $T_{u}(z)$ and $T_{e}(z)$ were identified to be equal to 1 . 


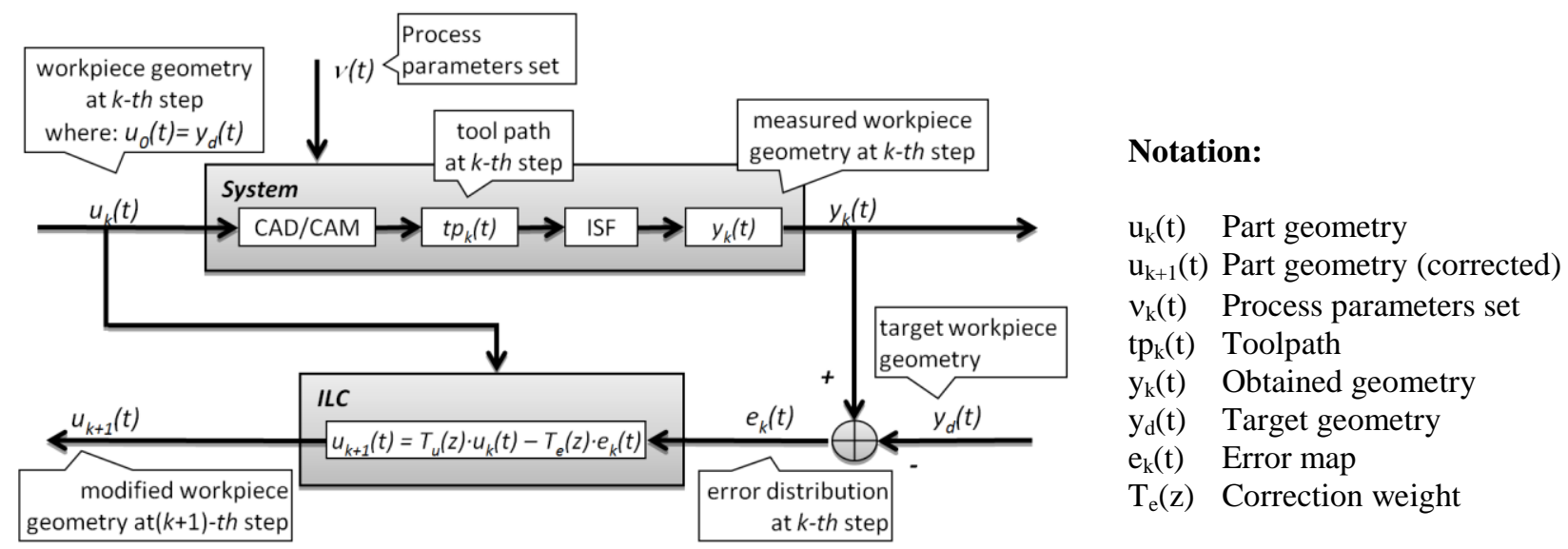

Fig. 2 ILC algorithm for reducing geometrical error in ISF parts.

The ILC was implemented in a self-developed software which loads the CAD geometry $u_{k}(t)$ and generates the toolpath $t p_{k}(t)$ for the ISF process [35]. Once the part is formed, its geometry $y_{k}(t)$ is acquired (measured in the case of experiments or exported in the case of simulations). Then, the software aligns $y_{k}(t)$ with the target $y_{d}(t)$ and estimates the geometrical error $e_{k}(t)$ of the formed part. Since $y_{k}(t)$ and $y_{d}(t)$ data are organized in a mesh format, their nodes do not correspond. Therefore the software projects the nodes of $y_{d}(t)$ on $y_{k}(t)$ mesh and estimates $e_{k}(t)$ as the distance between the node and each projection (Fig. 3).

In this way, $u_{k}(t)$ and $e_{k}(t)$ are defined for the same nodes and the corrected CAD geometry $u_{k+1}(t)$ can be estimated according to (4). In particular, $u_{k+1}(t)$ is obtained by moving the nodes of $u_{k}(t)$ along their respective normal direction to the part surface (Fig. 4) that was estimated as the vector sum of the normal directions of the surrounding facets. Moreover, an almost uniform mesh in terms of triangle dimensions was used to balance the normal estimations.

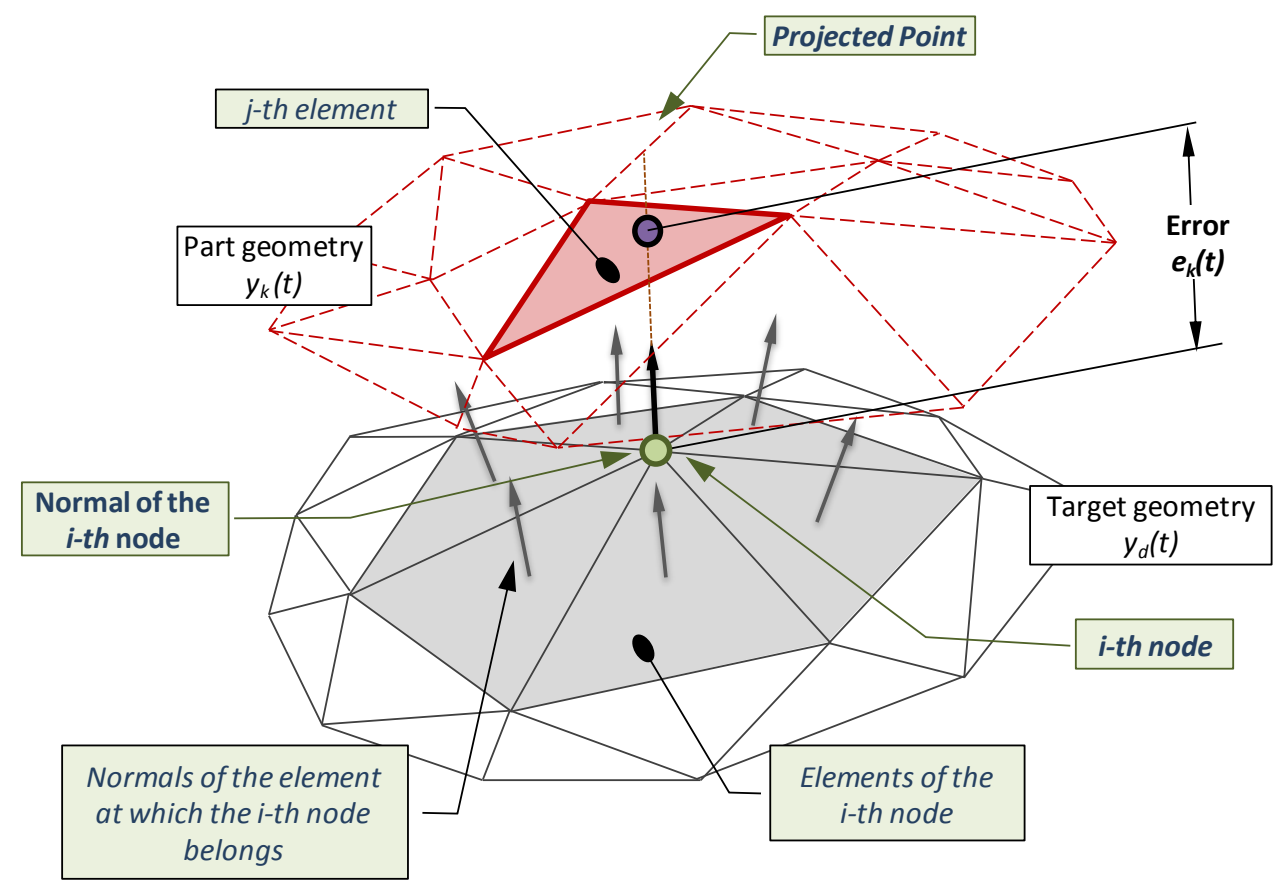

Fig. 3 Scheme of the error $e_{k}(t)$ calculation. 


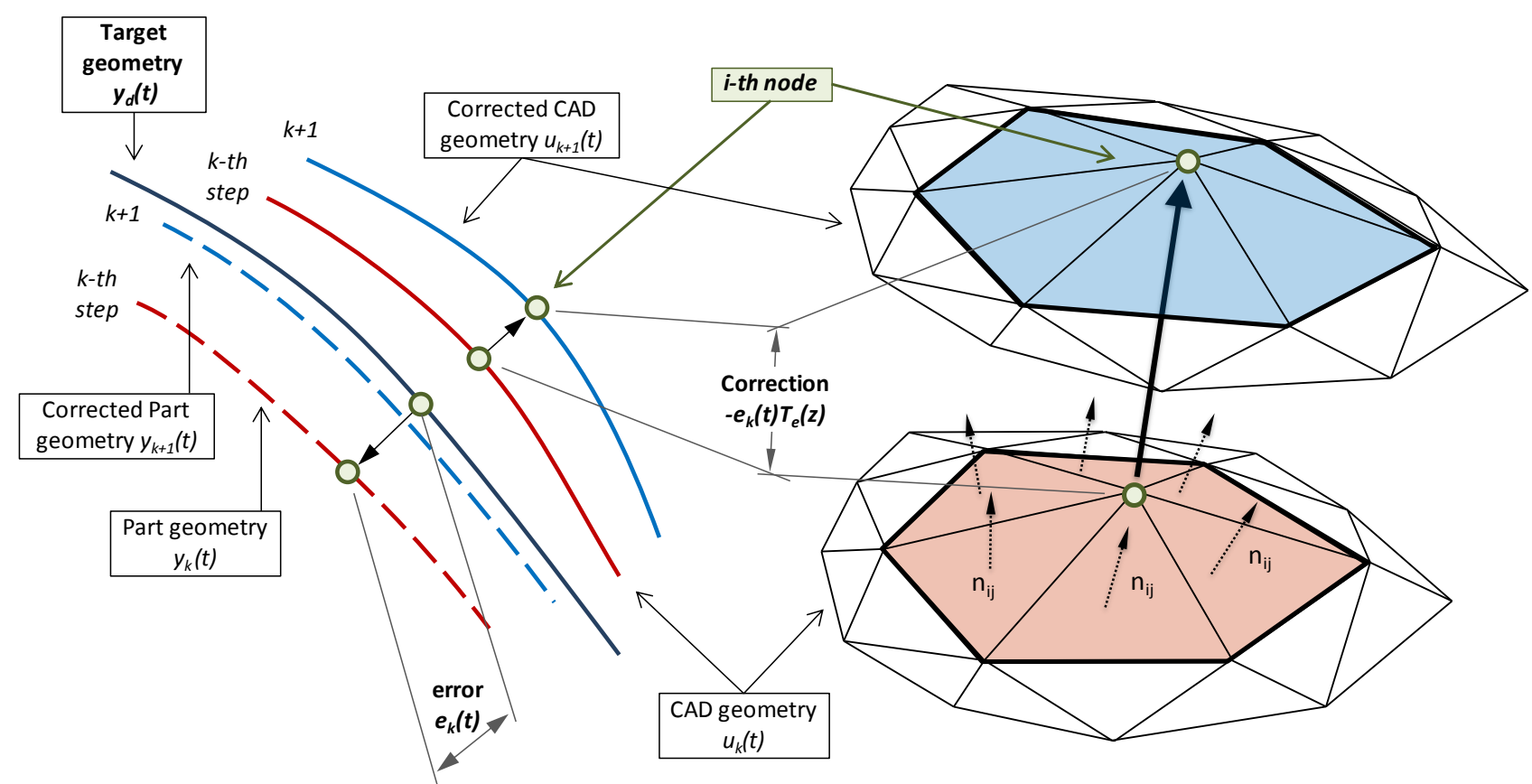

Fig. 4 Scheme of the correction phase of the algorithm (part profile and 3D).

\section{ILC case studies}

The ILC was applied to the asymmetric part reported in Fig. 5 that was designed for testing different ISF manufacturing features. In particular, it requires a toolpath that is parallel, orthogonal and transversal to the sheet rolling direction. Moreover, its walls have planar and curvilinear geometries and different leanings $\left(0^{\circ}, 29^{\circ}\right.$ and $\left.38^{\circ}\right)$. Finally, the part is $150 \times 150 \mathrm{~mm}$ in plane (excluding flanges) and $30 \mathrm{~mm}$ in depth. Previous researches showed that the considered geometry is able to give a not symmetric error map that depends on the local features (as wall leaning or distance from the boundaries) and the transitions between them [35]. Because of the need of using a clamping system to hold the blank, the correction algorithm was applied to the areas that are not in contact with the backing plate during forming so to avoid changes at the boundary of the blank and to compensate the error in all the directions.

Different materials in terms of formability were chosen (Table 1): a soft aluminium alloy (Al 1050A), a deep drawing steel (DC04) and a difficult to cold-form titanium alloy (Ti CP GR2). The flow stress laws of the material were determined by tensile tests while their elastic moduli were obtained from materials database. Moreover, with the idea of increasing the collateral deformations described in Fig. 1, a toolpath with a high step depth $(\Delta \mathrm{Z}=0.5 \mathrm{~mm})$ was adopted in order to induce higher deformations and to increase the forming force acting on the part. Furthermore, according to the experience gained in the previous researches [33,35], a lower step depth $(\Delta \mathrm{Z}=0.1 \mathrm{~mm})$ was adopted on the flat bottom of the part so to correct the pillow effect. 

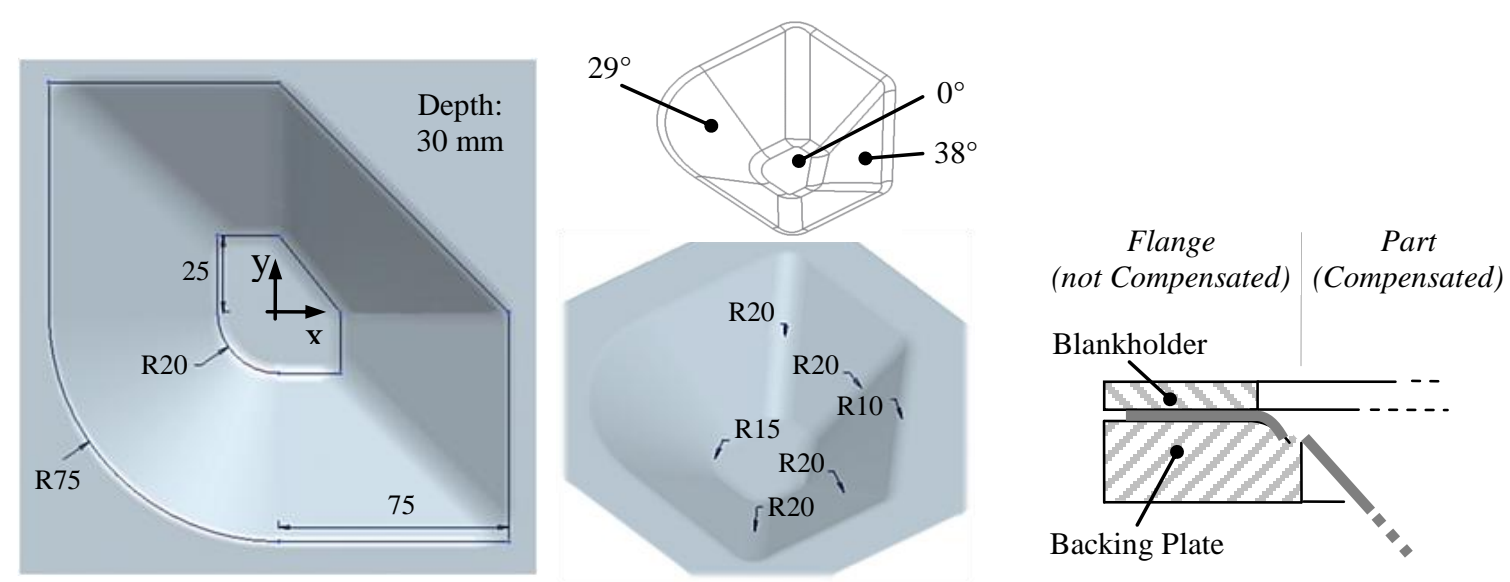

Fig. 5 Geometry of the formed part and clamping system of the blank.

Table 1 Experimental and simulative campaign.

\section{Blank properties}

\begin{tabular}{|c|c|c|c|}
\hline $\begin{array}{r}\text { Material } \\
\text { Flow Stress }{ }^{(*)} \\
\sigma=\mathrm{K} \cdot \varepsilon^{\mathrm{n}} \\
\text { Elastic Module }(\mathrm{E})\end{array}$ & $\begin{array}{c}\text { Al 1050A } \\
1 \mathrm{~mm} \\
\mathrm{~K}=118.6 \mathrm{MPa} \\
\mathrm{n}=0.208 \\
60.9 \mathrm{GPa} \\
\end{array}$ & $\begin{array}{c}\mathrm{DC} 04 \\
1 \mathrm{~mm} \\
\mathrm{~K}=534 \mathrm{MPa} \\
\mathrm{n}=0.232 \\
185 \mathrm{GPa} \\
\end{array}$ & $\begin{array}{c}\text { Ti CP Gr.2 } \\
0.5 \mathrm{~mm} \\
\mathrm{~K}=640 \mathrm{MPa} \\
\mathrm{n}=0.120 \\
106 \mathrm{GPa} \\
\end{array}$ \\
\hline \multicolumn{4}{|c|}{ Process parameters } \\
\hline & $\underline{F E M}$ & \multicolumn{2}{|r|}{ Experiments } \\
\hline $\begin{array}{r}\text { Blank Holder } \\
\text { Lubricant }\end{array}$ & $\begin{array}{c}20 \mathrm{kN} \\
\mu=0.12\end{array}$ & \multicolumn{2}{|c|}{$\begin{array}{l}\text { Fixed } \\
\text { Grease }\end{array}$} \\
\hline $\begin{array}{r}\Delta \mathrm{Z} \\
\text { Punch speed } \\
\text { Punch }\end{array}$ & \multicolumn{3}{|c|}{$\begin{array}{c}\text { Walls: } 0.5 \mathrm{~mm} \\
\text { Bottom }^{(* *)}: 0.1 \mathrm{~mm}\end{array}$} \\
\hline
\end{tabular}

\subsection{ILC applied to FEM}

The ILC method requires to manufacture a part for each iteration step. Therefore, the possibility to use a FEM model to simulate the forming process was investigated with the aim of reducing the number of parts to be manufactured.

The process was simulated using a two steps FEM model that was developed using PamStamp $2 \mathrm{G}^{\circledR}$ code. In the first step, the blank is held between the blank holder and the backing plate by a high clamping force $(20 \mathrm{kN})$ to avoid sheet sliding while the ISF process takes place. In the second step, tools and fixtures are removed and sheet springback is simulated. The second step was necessary because preliminary simulations showed that this was fundamental for improving the accuracy of Ti CP GR2 simulations with respect to the actual process, while for Al 1050A and DC04 alloys the results were not significantly affected by the springback phenomenon [38]. The simulation (both steps) of a single iteration of the ILC required approximately 2.5 hours on a 8 CPU@3.07 GHz computer.

Simulations were run accordingly to the data reported in Table 1 and the geometry of the formed part $y_{k}(t)$ was used to implement the ILC method in Fig. 2. In particular, iterations where run until 
convergence which occurred for $\mathrm{Al} 1050 \mathrm{~A}$ at $\mathrm{k}=3$ (-1.7\% of variation in the error scattering), for DC04 at $\mathrm{k}=4$ (-3.4\% of variation) and for Ti CP GR2 at $\mathrm{k}=4$ (4.7\% of variation).

In order to validate the FEM model, actual parts were manufactured using a CNC incremental forming machine and the toolpaths $t p_{k}(t)$ at the first $(\mathrm{k}=0)$ and last (convergence of the ILC) iteration steps. In particular, the validation was performed comparing thinning and geometry of the parts.

The part thinning was compared at the first and final steps along the six wall profiles reported in Fig. 6. The thinning on the considered walls is almost uniform (Fig. 6a), therefore an average value along each wall was used for the comparison. Fig. $6 \mathrm{~b}$ shows that the FEM is capable of estimating the sheet thinning with a high accuracy (difference of about $\pm 3 \%$ ), particularly for the deep drawing DC04 steel, with a tendency to a slight overestimation.

a)

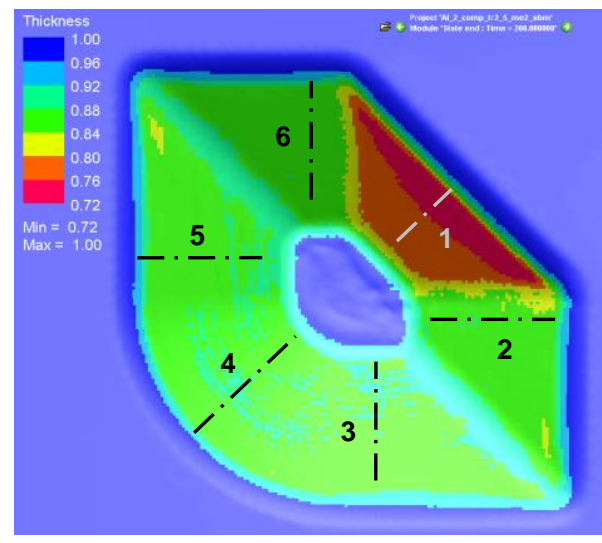

b)

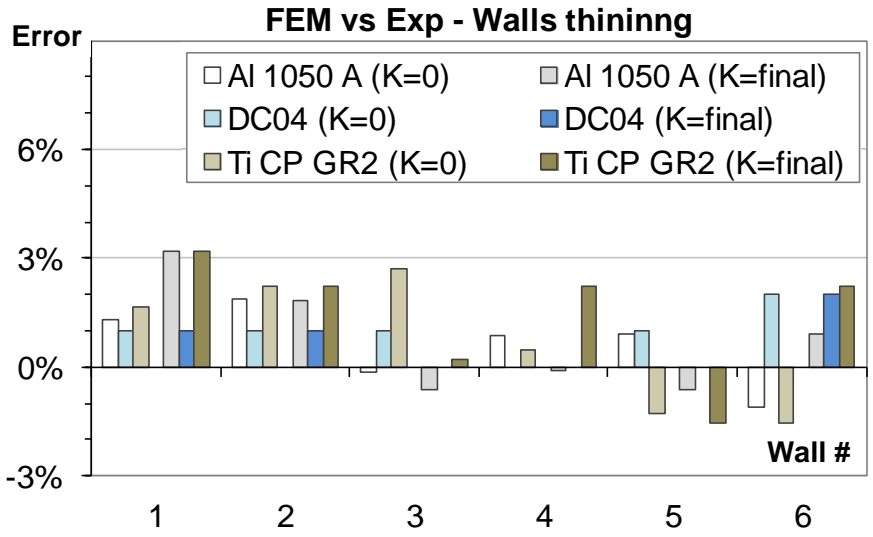

Fig. 6 Part thickness at the end of the forming process. a) Areas considered for the comparison and b) comparison between FEM and experimental results.

Fig. 7 reports an example of the evolution of the part accuracy when ILC and FEM are used together. The figures show, at different steps, the map of the geometrical errors and their frequency distributions. The error map was obtained by aligning part and target geometries and evaluating the distances between them. In general, the geometrical error becomes more uniform and normally distributed as the compensation proceeds. For these reasons, the results on the geometrical accuracy of the part were compared in terms of average value (corresponding to the $50 \%$ of the frequency curve area) and the scattering (range covering the $99.73 \%$ of the curve area).
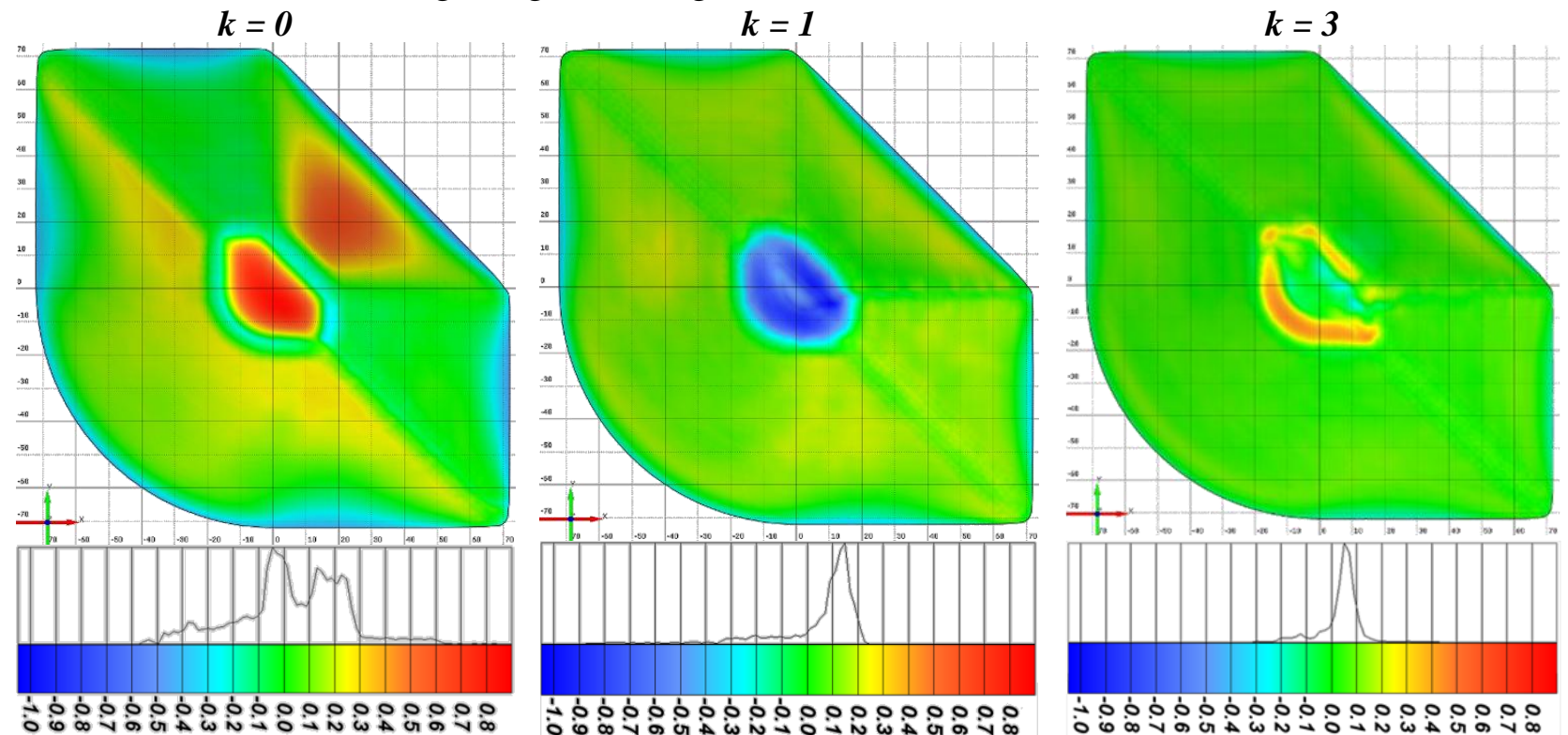

Fig. 7 FEM simulations Al 1050A - Geometrical error of the part (map and frequency distribution) at the $\mathrm{k}$-th iteration step of the ILC (dimensions: $\mathrm{mm}$ ). 
The results on the FEM accuracy in predicting the geometry of the part are reported in Fig. 8 and Fig. 9. In particular, FEM and experimental geometries were individually compared with the target one and then compared. Fig. 8a to Fig. 8c show the distributions of the distance between the two geometries on the whole part while Fig. 8d compares the corresponding error scattering. Results show that the precision of the FEM model depends on the sheet material. In particular, it can reach a satisfactory precision lower than $\pm 0.5 \mathrm{~mm}$ for $\mathrm{Al} 1050 \mathrm{~A}$ and DC04 blanks at the last step ( $\pm 0.33 \mathrm{~mm}$ and $\pm 0.45 \mathrm{~mm}$ respectively). In the case of Ti CP GR2 alloy, the FEM is less precise and reaches an accuracy of about $\pm 1.1 \mathrm{~mm}$.

\section{FEM Vs Exp - Part geometry $(k=0)$}
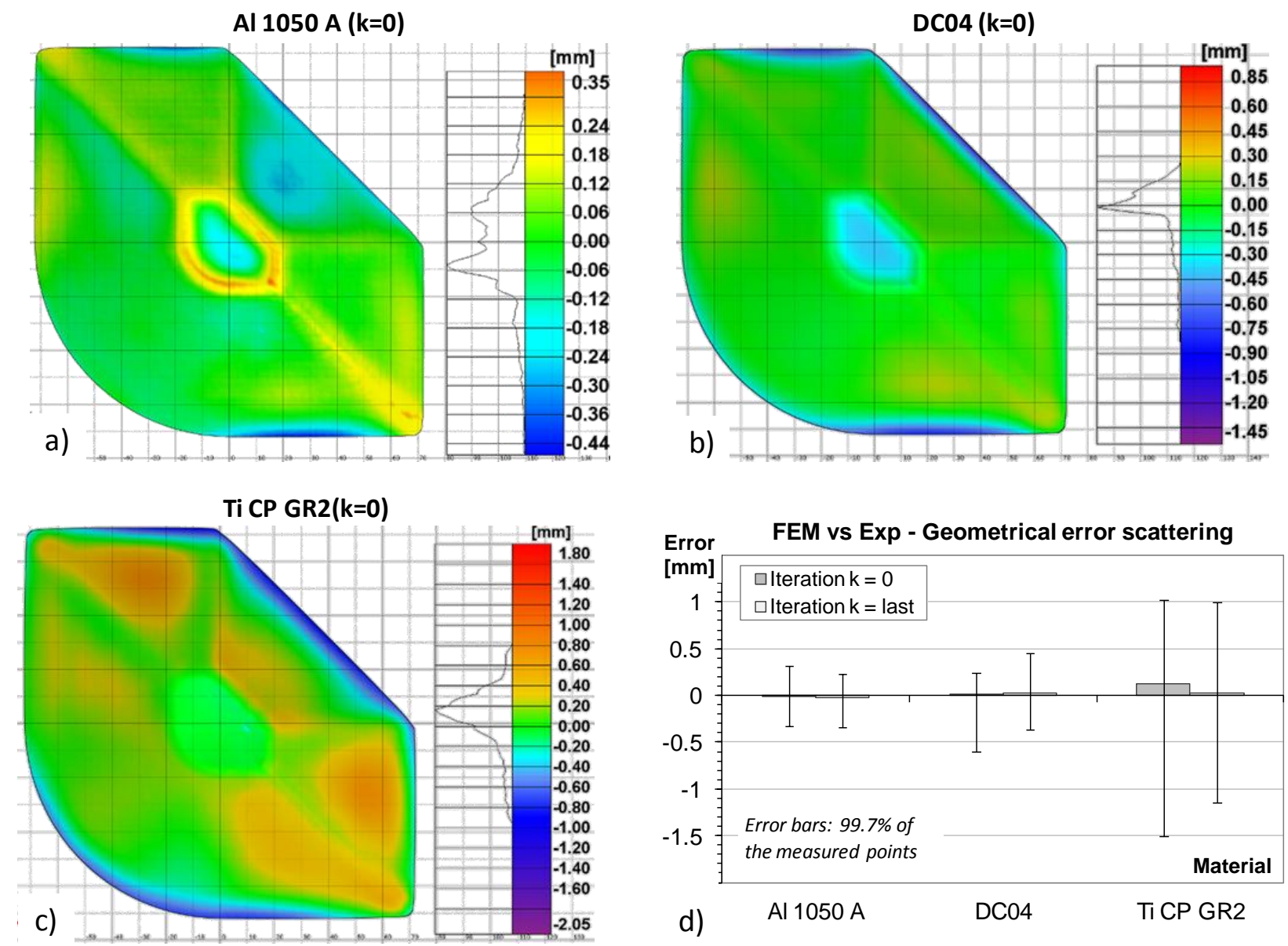

Fig. 8 Comparison between FEM and experimental results. Contour plots of the geometrical error (map and frequency distribution) for a) $\mathrm{Al} 1050 \mathrm{~A} \mathrm{~b}) \mathrm{DC} 04$ c) Ti CP GR2 and d) error scattering (dimensions: mm).

Fig. 9 reports the evolution of the part accuracy (compared to the target geometry) when the ILC is applied to FEM simulations in terms of average error and its scattering at the end of each iteration step. Moreover, the results obtained in the experiments using the same toolpaths of FEM simulations are reported for comparison. At the first step $(\mathrm{k}=0)$, there is a high overlapping but the FEM diverges from experiments as the ILC compensation proceeds ( $\mathrm{k}=$ final). Moreover, the difference between FEM and experiments depends on the material formed. In fact, for Al 1050A and DC04 alloys, the accuracy of the final part is comparable with a precision of $\pm 0.5 \mathrm{~mm}$ (respectively [-0.35;0-47] and [-0.53;0.53] mm) while for Ti CP GR2 it is higher ([-0.92;0.83] mm). According to these results, the FEM is capable to model the process in terms of part thickness (Fig. 6) and part geometry (Fig. 9, $\mathrm{k}=0$ ). Moreover, within the ILC, the FEM is capable to improve the part accuracy up to the desired range of $\pm 0.5 \mathrm{~mm}$ (Fig. 9). Besides this, the negligible differences with experiments interact with the ILC algorithm accumulating errors (Fig. 9, $\mathrm{k}=$ final). These 
interactions are not significant when forming $\mathrm{Al}$ 1050A and DC04 alloys while they are consistent for Ti CP GR2.

In order to try to improve the accuracy of the titanium part and to better understand how the material could affect the capability of the ILC method, further experimental tests were conducted and reported in section 3.2.
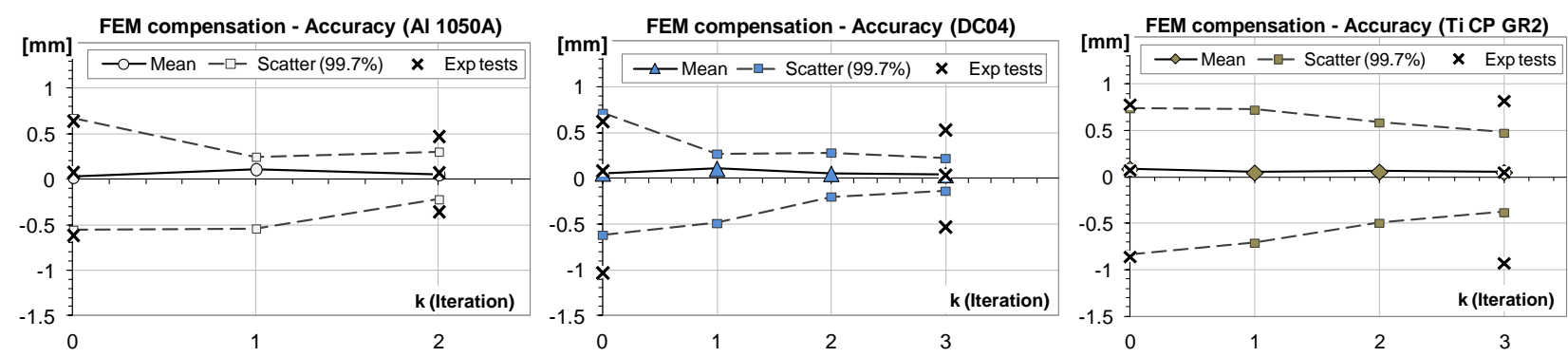

Fig. 9 Results of the ILC applied to FEM simulations. The average error and its scattering at the end of each iteration step are reported for the tested blanks in FEM and experiments.

\subsection{ILC applied to experimental tests}

The results showed in section 3.1 underlined that the material properties are related to the FEM precisions and the ILC capability. Therefore, an experimental campaign was carried out using the ILC with an experimental forming process. Parts were formed according to Table 1, using a CNC machine [39] and measuring the geometry of the formed parts with the optical scanner 3D RevEng Hi-Res LE 240 (accuracy $\pm 0.08 \mathrm{~mm}$ ). The ILC compensation was cycled until convergence that was reached for $\mathrm{Al} 1050 \mathrm{~A}$ at $\mathrm{k}=3(-3.3 \%$ of variation in the error scattering), for DC04 at $\mathrm{k}=4(2.7 \%$ of variation) and for Ti CP GR2 at $\mathrm{k}=4$ (4.4\% of variation).

Fig. 10 shows the results on the part precision in terms of average error and its scattering at each iteration step. Trends are similar to what afore observed (Fig. 7 and Fig. 9). In fact, the algorithm converges in few iterations, the part final accuracy is good for $\mathrm{Al} 1050 \mathrm{~A}$ (about $\pm 0.28 \mathrm{~mm}$ ) and DC04 (about $\pm 0.4 \mathrm{~mm}$ ), while Ti CP GR2 shows better results with respect to the FEM approach, but the error scattering remains high $([-0.82 ; 0.56] \mathrm{mm})$.
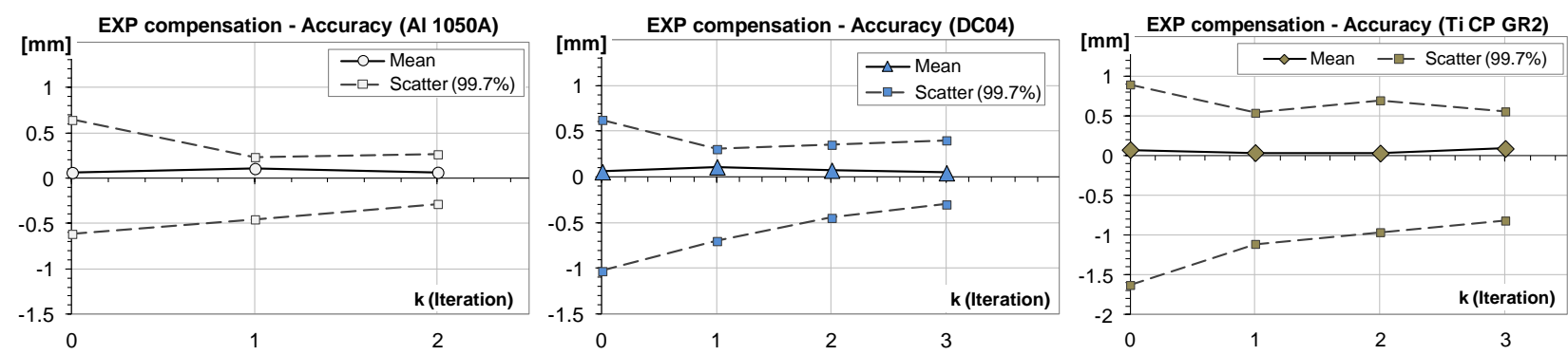

Fig. 10 Result of the ILC applied to the experimental campaign. The average error and its scattering at the end of each iteration step are reported.

\section{Results discussion}

\subsection{Part accuracy and material properties}

Both test campaigns based on FEM and error experimental compensations showed that the achievable part accuracy depends on the formed material. Therefore, the material properties were considered to further investigate this aspect (Table 1). In particular, the material strength (K) was chosen to indicate the ductility and the young modulus (E) to represent the stiffness and the tendency to springback. Fig. 11 reports the amplitude of the error scattering obtained at the first $(\mathrm{k}=0)$ and final $(\mathrm{k}=$ final $)$ steps as a function of the $\mathrm{K} / \mathrm{E}$ ratio. The results at the first step represent the geometrical accuracy on the incrementally formed parts without error compensation (i.e. the 
accuracy of the ISF process itself), while the results at the last step represent the accuracy that can be achieved using the ILC. In both cases, results show that the achievable part accuracy depends linearly on the K/E ratio. This can be explained by considering the effects of $\mathrm{K}$ and $\mathrm{E}$ on the sheet stretching and springback that increase the geometrical error of the part (Fig. 1). In particular, a lower $\mathrm{K}$ value indicates a more ductile material which has a lower tendency to springback and increases the precision of ISF process [21]. Moreover, a higher E value generally leads to higher springback but, on the other hand, it increases the rigidity of the blank so either reducing the counter deformations due to stretching effects and increasing local deformation and embossment. In fact, the use of a more rigid forming system has proved to increase the part precision [15,40] while over-deformation and embossing are normally used methods to reduce springback [41]. Therefore, the effect of the ILC is to improve the ISF process reducing the effects of the material properties on process precision; its effectiveness depends on the material properties of the blank formed (Fig. 11, $\mathrm{k}=$ final). Finally, assuming to form a material which is highly deformable or has a rigidity which is much higher than its strength (i.e K/E tends to zero), the described effects are emphasized so leading the geometrical error to its lower limit. To support this example, the data trend reported in Fig. $11(\mathrm{k}=$ final) show that the scattering amplitude reached for $\mathrm{K} / \mathrm{E}=0$ is comparable with the measuring system one $(0.16 \mathrm{~mm})$.

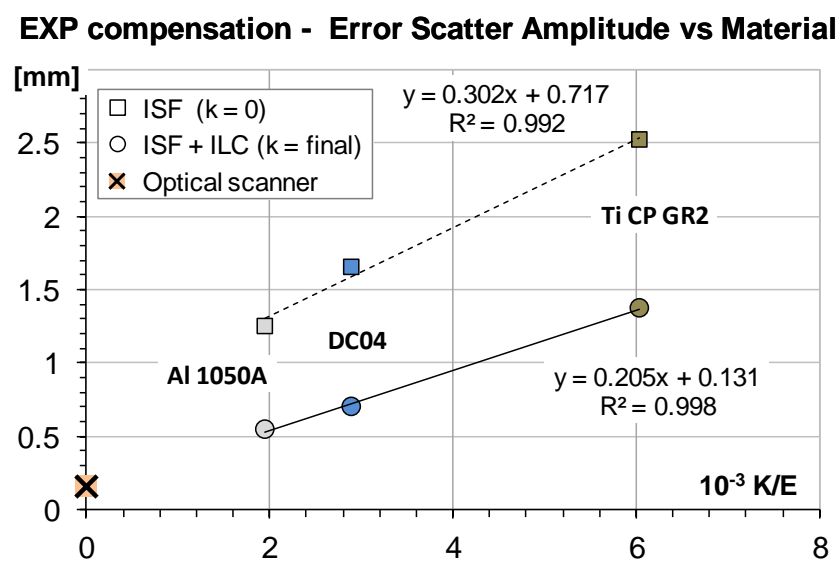

Fig. 11 Influence of the strength to elasticity ratio $(\mathrm{K} / \mathrm{E})$ on the part precision for the uncompensated $(\mathrm{k}=0)$ and compensated $(\mathrm{k}=$ final) part. The accuracy of the geometrical measuring system is reported for comparison.

\subsection{General remarks}

According to the collected data and the previous discussion, the results on the ISF process and the ILC method can be summarized as follows:

- The precision of incrementally formed parts is linearly affected by the material strength to elasticity ratio $(\mathrm{K} / \mathrm{E})$. In particular, the lower $\mathrm{K} / \mathrm{E}$ the higher the precision.

- The ILC algorithm allows enhancing the geometrical accuracy of the ISF process in few iteration steps (3 to 4 ) by compensating the geometrical error on the part ( $45 \%$ to $58 \%$ reduction in scattering) and reducing the influence of the material properties on the process.

- In high deformation conditions (i.e. high step depths), the ILC is capable to achieve an accuracy similar to traditional stamping techniques $( \pm 0.5 \mathrm{~mm})$ for mild (aluminium) and ductile (deep drawing steel) alloys. When difficult to form materials are considered (as in the case of titanium), the accuracy is lower but the reduction of the error is high $(45 \%$ in scattering). The lower reduction of the error could be caused by the blank material (and in particular to its elasticity) which acts as a damper for the ILC algorithm. In other words, when the error is compensated by over (or under) forming the blank, the material elasticity tends to recover a part of the deformation so reducing the imposed geometrical correction and the effectiveness of the ILC compensation. Under the corrections weight $T_{e}(z)$ point of view, the 
damping has the effect of reducing its actual value. Therefore, to further improve the accuracy of the parts, it is possible to implement a damping coefficient in the ILC or to directly use a weight value $T_{e}(Z) \geq 1$.

- FEM simulations can be used to correct the error for the first iteration steps, then the compensated part can be manufactured. Anyway, it has to be taken into account that negligible approximations of the numerical model are accumulated at each iteration of the ILC so leading to a progressive inaccuracy of the FEM results. Even in this case, the divergence depends on the material and is acceptable when forming mild and ductile alloys. More precise and complex numerical models could be developed to improve ILC precision focusing probably on the material characterization and on the springback modelling.

\section{Conclusions}

The tests presented in this work showed how the precision of ISF is strongly influenced by the material properties of the blank. In particular, the strength to elasticity ratio is directly related to the scattering of the geometrical error of the part because of its influence on the rigidity of the forming system and the sheet springback.

ILC showed to be an effective method to enhance the precision of the process when forming a wide range of materials, from the mild aluminium to the hard to form titanium alloys both in the case of low and high step depths of the toolpath. Besides this, its capability is still influenced by the material properties. In particular it allows to reach a part precisions which is competitive with traditional process (within $\pm 0.5 \mathrm{~mm}$ ) in the case of aluminium and deep drawing steel, while it is higher (anyhow within $\pm 0.8 \mathrm{~mm}$ ) when forming titanium alloys.

Similar results were achieved by using ILC and FEM simulations together to preliminarily compensate the geometrical error so to manufacture only the final part. In this case, the small approximations of the numerical model are accumulated at each iteration of the ILC so leading to a divergence between FEM and experiments. This divergence is acceptable when forming aluminium and deep drawing steel.

Some aspects deserve further investigations as the possibility that the material springback acts like a damper for the error compensation method. Therefore, the ILC will be enhanced considering a damping effect in its implementation. Moreover, efforts will be dedicated to improve the precision of the FEM model to reduce the divergence as the ILC iteration proceeds.

\section{Acknowledgements}

Compliance with Ethical Standards:

Funding: This study was funded by the Italian Ministry of Economic Development (grant number MI01_00237), “Michelangelo" project.

\section{References}

[1] Leszak E (1967) Apparatus and Process for Incremental Dieless Forming, US. Patent US3342051A1, Published September 191967.

[2] Jeswiet J, Geiger M, Engel U, Kleiner M, Schikorra M, Duflou J, Neugebauer R, Bariani P, Bruschi S (2008) Metal forming progress since 2000. CIRP Journal of Manufacturing Science and Technology 1:2-17. doi: 10.1016/j.cirpj.2008.06.005

[3] Nimbalkar DH, Nandedkar VM (2013) Review of Incremental Forming of Sheet Metal Components. Int J of Engineering Research and Application 3(5):39-51

[4] Emmens WC, Sebastiani G, Van den Boogaard AH (2010) The technology of Incremental Sheet Forming - A brief review of the history. J of Mat Proc Tech 210:981-997. doi:10.1016/j.jmatprotec.2010.02.014

[5] Jeswiet J, Micari F, Hirt G, Bramley A, Duflou JR, Allwood J (2005) Asymmetric single point incremental forming of sheet metal. Annals of the CIRP 54(2):623-649. doi:10.1016/S00078506(07)60021-3 
[6] Fiorentino A, Marzi R, Ceretti E (2012) Preliminary results on Ti Incremental Sheet Forming (ISF) of biomedical devices: biocompatibility, surface finishing and treatment. Int $\mathbf{J}$ of Mechatronics and Manuf System 5(1):36-45. doi:10.1504/IJMMS.2012.046146

[7] Mitsuishi M, Cao J, Bartolo P, Friedrich D, Shih AJ, Rajurkar K, Sugita N, Harada K (2013) Biomanufacturing. Annals of the CIRP 62(2):585-606. doi:10.1016/j.cirp.2013.05.001

[8] Bagudanch I, Garcia-Romeu ML, Ferrer I, Lupiañez J (2013) The Effect of Process Parameters on the Energy Consumption in Single Point Incremental Forming. Procedia Engineering 63:346-353. doi:10.1016/j.proeng.2013.08.208

[9] Filice L, Fratini L, Micari F (2002) Analysis of Material Formability in Incremental Forming. Annals of the CIRP 51(1):199-202

[10] Ham M, Jeswiet J (2007) Forming Limit Curves in Single Point Incremental Forming. Annals of the CIRP 56(1):277-280. doi:10.1016/j.cirp.2007.05.064

[11] Khalatbari H, Iqbal A, Shi X, Gao L, Hussain G, Hashemipour M (2015) High-Speed Incremental Forming Process: A Trade-Off between Formability and Time Efficiency. Materials and Manufacturing Processes 30(11):1354-1363. doi: 10.1080/10426914.2015.1037892

[12] Fiorentino A, Marenda GP, Marzi R, Ceretti E, Kemmoku DT, Lopes Da Silva JV (2012) Rapid prototyping techniques for individualized medical prosthesis manufacturing. In: Bartolo $P$ et al (ed) Innovative Developments in Virtual and Physical Prototyping - Proceedings of the 5th International Conference on Advanced Research and Rapid Prototyping. CRC Press, London, pp 589-594

[13] Hussain G, Mahna A, Iqbal A (2016) Response Surface Analysis of Cold Formability of Polymers in Incremental Sheet Forming: Effect of Parameters and Associated Thermal Softening. Int $\mathrm{J}$ Of Precision Engineering and Manufacturing 17(5):613-621. doi: 10.1007/s 12541-016-0074-0

[14] Duflou JR, Lauwers B, Verbert J (2007) Study on the Achievable Accuracy in Single Point Incremental Forming. In: Banabic D. (ed) Advanced Methods in Material Forming. Springer Berlin Heidelberg, pp 251-262. ISBN: 978-3-540-69844-9

[15] Fiorentino A, Attanasio A, Marzi R, Ceretti E, Giardini C (2011) On forces, formability and geometrical error in metal incremental sheet forming. Int $\mathbf{J}$ of Mat and Product Tech 40(34):277-295. doi:10.1504/IJMPT.2011

[16] Micari F, Ambrogio G, Filice L (2007) Shape and dimensional accuracy in Single Point Incremental Forming: State of the art and future trends. J of Mat Proc Tech 191:390-395. doi:10.1016/j.jmatprotec.2007.03.066

[17] Guzmán CF, Gu J, Duflou JR, Vanhove H, Flores P, Habraken AM (2012) Study of the geometrical inaccuracy on a SPIF two-slope pyramid by finite element simulations. Int $\mathbf{J}$ of Solids and Structures 49:3594-3604. doi:10.1016/j.ijsolstr.2012.07.016

[18] Duflou JR, Lauwers B, Verbert J, Tunckol Y, De Baerdemaeker H (2005) Achievable Accuracy in Single Point Incremental Forming: Case Studies. In: Banabic D (ed) Proceedings of 8th ESAFORM Conference on Material Forming. Publishing House of the Romanian Academy, Cluj-Napoca, pp 675-678. ISBN 973-27-1173-6

[19] Meier H, Buff B, Laurischkat R, Smukala V (2009) Increasing the part accuracy in dieless robot-based incremental sheet metal forming. Annals of the CIRP 58:233-238. doi:10.1016/j.cirp.2009.03.056

[20] Li j, Bai T, Zhou Z (2014) Numerical simulation and experimental investigation of incremental sheet forming with an elastic support. Int J Adv Manuf Technol 74:1649-1654. doi: 10.1007/s00170-014-6117-8

[21] Neugebauer R, Altan T, Geiger M, Kleiner M, Sterzing A (2006) Sheet metal forming at elevated temperatures. Annals of the CIRP 55(2):793-816. doi:10.1016/j.cirp.2006.10.008 
[22] Duflou JR, Callebaut B, Verbert J, De Baerdemaeker H (2007) Laser assisted incremental forming: formability and accuracy improvement. Annals of the CIRP 56(1):273-276. doi:10.1016/j.cirp.2007.05.063

[23] Duflou JR, Callebaut B, Verbert J, De Baerdemaeker H (2007) Improved SPIF performance through dynamic local heating. Int $J$ of Machine Tools and Manufacture 48(5):543-549. doi:10.1016/j.ijmachtools.2007.08.010

[24] Xu D, Wu W, Malhotra R, Chen J, Lu B, Cao J (2013) Mechanism investigation for the influence of tool rotation and laser surface texturing (LST) on formability in single point incremental forming. Int $\mathrm{J}$ of Machine Tools and Manufacture 73:37-46. doi:10.1016/j.ijmachtools.2013.06.007

[25] Liu Z, Daniel WJT, Li Y, Liu S, Meehan PA (2014) Multi-pass deformation design for incremental sheet forming: Analytical modeling, finite element analysis and experimental validation. J of Mat Proc Tech 214:620-634. doi:10.1016/j.jmatprotec.2013.11.010

[26] Bambach M, Araghi BT, Hirt G. Strategies to improve the geometric accuracy in asymmetric single point incremental forming (2009) Production Engineering 3:145-156. doi:10.1007/s11740-009-0150-8

[27] Malhotra R, Bhattacharya A, Kumar A, Reddy NV, Cao J (2011) A new methodology for multi-pass single point incremental forming with mixed toolpaths. Annals of the CIRP 60(1):323-326. doi:10.1016/j.cirp.2011.03.145

[28] Duflou JR, Verbert J, Belkassem B, Gu J, Sol H, Henrard C, Habraken AM (2008) Process window enhancement for single point incremental forming through multi-step toolpaths. Annals of the CIRP 57(1):253-256. doi:10.1016/j.cirp.2008.03.030

[29] Junchao L, Junjian S, Bin WA (2013) multipass incremental sheet forming strategy of a car taillight bracket. Int J of Adv Manuf Technol 69:2229-2236. doi:10.1007/s00170-013-5179-3

[30] Rauch M, Hascoet JY, Hamann JC, Plenel Y (2009) Tool path programming optimization for incremental sheet forming applications. Computer-Aided Design 41:877-885

[31] Allwood JM, Music O, Raithathna A, Duncan SR (2009) Closed-loop feedback control of product properties in flexible metal forming processes with mobile tools. Annals of the CIRP 58:287-290

[32] Fu Z, Mo J, Han F, Gong P (2013) Tool path correction algorithm for single-point incremental forming of sheet metal. Int J Adv Manuf Technol 64:1239-1248

[33] Fiorentino A, Giardini C, Ceretti E (2015) Application of artificial cognitive system to incremental sheet forming machine tools for part precision improvement. Precision Engineering 39:167-172. doi:10.1016/j.precisioneng.2014.08.005

[34] Fiorentino A, Ceretti E, Feriti GC, Giardini C (2015) Improving accuracy in Aluminum Incremental Sheet Forming of complex geometries using Iterative Learning Control. Key Engineering Materials 651-653:1096-1102. doi: 10.4028/www.scientific.net/KEM.651653.1096

[35] Fiorentino A, Feriti GC, Giardini C, Ceretti E (2015) Part precision improvement in Incremental Sheet Forming of not axisymmetric parts using an Artificial Cognitive System. J of Manufacturing Systems 35:215-222. doi:10.1016/j.jmsy.2015.02.003

[36] Moore KL (1993) Iterative Learning Control for Deterministic System. Springer-Verlag, London.

[37] ISO 1101:2012. Technical drawings, Geometrical tolerancing, Tolerancing of form, orientation, location and run-out

[38] Fiorentino A, Feriti GC, Ceretti E, Giardini C, Bort CMG, Bosetti P (2014) Development of tool path correction algorithm in Incremental Sheet Forming. Key Engineering Materials 662663:382-389. doi: 10.4028/www.scientific.net/KEM.622-623.382

[39] Attanasio A, Fiorentino A, Mazzoni L, Ceretti E, Giardini C (2008) Design of an Equipment for Forces Measurement in TPIF Process. In: Yang DY (ed) Proceeding of the 9th ICTP. Hanrimweon, Seoul, pp 1783-1788. doi:10.1504/IJMPT.2011.039936 
[40] Garcia-Romeu ML, Pérez-Santiago R, Bagudanch I (2013) Fabrication of a biopsy mesoforceps prototype with incremental sheet forming variants. Int $\mathrm{J}$ of Mechatronics and Manufacturing Systems 6(3):242-253. doi:10.1504/IJMMS.2013.056451

[41] Altan T et al (1998) Metal forming handbook / Shuler. Springer-Verlag, New York. ISBN 3540-61185-1 